\title{
The New Ideas of higher Vocational col- leges Employment Guidance Work Based on the Questionnaire Survey
}

\author{
Huang Jianshe ${ }^{1}$ \\ (Zhejiang Business Technology Institute, 315012, Ningbo)
}

\begin{abstract}
In June 2011, our research group conducted a questionnaire survey. It is a relatively comprehensive survey aimed at employment guidance in higher vocational colleges. SPSS processing and analysis was applied to the research results and it has been founded that employment guidance of higher vocational colleges had little effect. The paper presents a new idea of vocational career guidance: to establish a long-term mechanism of employment guidance by building SNS online platform of employment guidance
\end{abstract}

Keywords: SNS Network; Questionnaire Survey; Employment Guidance; SPSS

\section{Introduction}

In order to carefully implement the spirit of the State Council files and to actively response to the pressure of the current employment of college graduates, our research group conducted a relatively comprehensive questionnaire survey in June 2011.It aims to have a general knowledge of pre-employment readiness, job expectations, and advises for the employment guidance of students in higher vocational colleges. In order to provide the basis for better employment guidance and teaching work of higher vocational colleges in the future, the paper gives a preliminary analysis of the questionnaire survey with SPSS $^{[1]}$ and provides a new advice: to build SNS online platform of employment guidance.

\section{Survey data and research methods}

The questionnaire survey was conducted on the employed freshmen, sophomore junior and senior of Vocational Colleges in Ningbo city. The appropriate survey proportion of them is respectively $20 \%$, $10 \%, 55 \%, 15 \%$.

This survey self-designed a questionnaire combined with the practical situation of the higher vocational colleges. The questionnaire focused on the current situation of school employment guidance, students' career planning, management of student's emotion, advises for job expectations and the employment situation as well as the preferred factors of determining the work unit. In addition, this survey also took interviews, case studies and other methods to gather effective information.According to the certain proportion, 2000 questionnaires were sent out and 1991 available questionnaires were retrieved including freshman 398, 199 sophomore, junior 1095, 299 students already employed. The ratio of callback of valid questionnaire is $99.5 \%$ which ensures the quality of the survey. 


\section{Statistical description and analysis}

Before Statistical description and analysis, it is necessary to translate text data of the survey into digital data, and then to complete the statistics by the computer as the number of questionnaire is big. This is what we called questionnaire coding. Simply to say, it is to encode and design the single answer and multiple choice of the questionnaire in accordance with SPSS rules. Specific design can be seen in the following statistical description and analysis of specific projects.

\subsection{Enactment of the "career plan- ning" and the Current Situation of implementation}

In this type of survey, it is mainly the multiple choices. There is only one answer in the multiple choices. According to the SPSS theory, encoding setting only accounts for one position.

For example: Do you have clear objectives for career development?

\section{$\bigcirc$ 1,very clear $\bigcirc$ 2,relatively clear $\bigcirc$ 3, less clear $\bigcirc$, not clear}

The answer is a single digital and the serial number can be filled into the corresponding column.

The frequency statistics of SPSS can be used directly to get the number of frequency and percentage of each option of the multiple choices. Statistical results show that most of the college students take things one step by step and do not have a clear career development goal, shown in table 1.

Table 1 Do you have clear objectives for career development?

\begin{tabular}{|l|l|}
\hline Options & Percentage \\
\hline A. very clear & $4.76 \%$ \\
\hline B. relatively clear & $27.05 \%$ \\
\hline C. less clear & $63.24 \%$ \\
\hline D. not clear & $4.94 \%$ \\
\hline
\end{tabular}

The result of survey on "your career planning and implementation" shows that most of the college students do their career planning only for the teacher's sake and pay nothing attention to the career planning itself. Moreover, even some students once have implemented their career planning; they may have not persisted without a supervisor. Only very few students implement their plans step-by-step with goals.

\subsection{Psychological demands and sta- tus of career development coun- seling of emotional management}

In this type of survey, most of the choices have more than one answer. The number of multiple choice options is uncertainty in SPSS using a multiple-choice dichotomy ${ }^{[2]}$ to encode them. That is the result of each option, is "0" or "option number", in another way, that is the selection of the code value is the serial number of the answer, for example:

When there is difficulty or confusion in the job search process, which means you will choose to solve the problems?

$\bigcirc 1$, trust school career center, counseling room $\bigcirc 2$, ask headmaster for help 3,communicating with brothers and sisters $\bigcirc 4$,ask friends and relativities for help $\bigcirc 5$,counseling on the website $\bigcirc 6$,don't know how do with it and do nothing with it $\bigcirc 7$,other (please specify)

In the questionnaire survey, the number of digital of the answer is the number of answers, where the "other" option can be considered as an answer. And just put the specification text of the "other" option directly attach to the back. In the above question, if a students selected 2, 3, 4, 5, 6,7 , and behind the seven options indicating the following words "by socioprofessional vocational training institu- 
tions", then it can be encoded as "234 567 by professional vocational training through social institutions".

Multiple response frequency statistics of SPSS software can calculate the frequency of various options in the multiplechoice (selected times), frequency percentage (an option is selected to be elected in the proportion of the total number of times at all the options, the sum of the frequency percentage of all the options is $100 \%$ ) and the percentage of valid samples (the number of each option to be chosen and the proportion of the number of the survey sample, the sum of sample percentage is greater than $100 \%$ ). Finally, to select and statistical count the keywords of the answer "other" option. The statistical results show that when students encounter difficulties in the process of choosing or when they are in confusion, though there are a variety of solution, but there are still a considerable part of students who are at a loss and do not know how to solve problems. As shown in Table 2 (Note: The number of the recovery of the survey sample is 1991 copies).

Table 2 shows the frequency distribution of seeking solution of college students in difficulty or confusion

\begin{tabular}{|l|l|l|l|}
\hline Sn & Freq & $\begin{array}{l}\text { Freq } \\
\text { percentage }\end{array}$ & $\begin{array}{l}\text { percentage } \\
\text { of samples }\end{array}$ \\
\hline 1 & 255.5 & $8.17 \%$ & $12.8 \%$ \\
\hline 2 & 690 & $22.07 \%$ & $34.65 \%$ \\
\hline 3 & 635.7 & $20.33 \%$ & $31.93 \%$ \\
\hline 4 & 704.5 & $22.53 \%$ & $37.42 \%$ \\
\hline 5 & 676 & $21.62 \%$ & $33.95 \%$ \\
\hline 6 & 102.6 & $3.28 \%$ & $5.15 \%$ \\
\hline 7 & 92.7 & $2.00 \%$ & $4.65 \%$ \\
\hline SUM & 3127 & $100 \%$ & $160.55 \%$ \\
\hline
\end{tabular}

So, to use the same statistics for other options to analyze the results thus it shows that the majority of students choose "not to go" in topic of "when you feel there are psychological problems, will you go to the school counseling center for consultation?". In face-to-face interview survey, when asked whether they want to have a professional personnel tracking guide their employment, students generally agreed.

\subsection{Current Situation of Vocational colleges' employment guidance}

Single and multiple investigation topics of this survey was done with the analysis and statistical methods mentioned above, it shows that the students attach great importance to school guidance work and $93.4 \%$ of the them think that it is necessary to open the school guidance lesson. Learning from the face-to-face interviews with students, employment guidance is limited to the open of a similar career planning courses in most of the vocational colleges which only includes a few open recruitments offered by some units. All of this is with little success. And courses of career planning offered by school are generally in large class and majority of teachers talk about the boring theory which do not means much.

In topic of "which ways you get access to employment related knowledge and interview skills", among the options of "from website, relativities, the experience of friends, career guidance courses and seminars organized by school", website , career guidance courses and seminars organized by school take a larger proportion. It shows that career guidance courses and seminars is boring but still matters a lot, at the same time, in this era of rapid dissemination of information, the power of the network can not be ignored.

In topic of "which ways do you take to seek a job?" most of the students chose "recruitment on the network", some of 
them take "relativities and friends", only a few of them take "the teachers from career guidance center". This fully shows that the role of vocational colleges' employment guidance in students looking for work is minimal while network and circle of friends is of great help.

\subsection{Expectations for the school career center}

The survey offered an open question: what kind of service you want to get from the school career center?

The option whose proportion is figured out relatively high is as following: 1 proficiency tests of character and interest, 2 assist in identifying career goals and supervising the implementation, 3 whole course of the professional education and guidance of psychological adjustment, 4 providing employment exchange platform, 5 professional knowledge of industry and job, 6 enhance training of general ability, 7 employment information, 8 resume production guidance, 9 Interview skills training.

As for the above nine options of the open questions, the research team does another small-scale survey and sorts the nine options according to their importance so as to find out the most concerned problems of students. The specific approach is: Let the students elected which is very important, important, in general, unimportant, very unimportant one or several options, and then using the SPSS statistical software to get the effective percentage of nine answers "W1, W2, ..., W9" in five options "very important, important, unimportant, very unimportant". Finally, according to SPSS satisfaction assessment ${ }^{[3]}$ statistical theory of a certain problem to get the "degree" of answers, namely $\mathrm{X} 1, \mathrm{X} 2, \ldots \mathrm{X} 9$. (The "degree" of each sequence weighted sum of the final outcome, it is used to measure the degree of importance of the
options).Assuming that the effective percentage of $\mathrm{X} 1$ in five options "very important, important, unimportant, very unimportant" are V1 and V2, .., V9 and the right degrees are 5,4,3,2,1, then:

The degree of $\mathrm{W} 1=$ [V1X5+V2X4+V3X3+V4X2+V5X1]/5 $\mathrm{X} 100 \%$

And so on, through the comparison of $\mathrm{W} 1 、 \mathrm{~W} 2 、 . . . . . \mathrm{W} 9$, the "degree of "importance came out, the result showed that what most of the students want to get is : the whole course and professional occupational psychological adjustment education and guidance.

\section{The countermeasure and the sug- gestion}

The above survey for students on the awareness and demand on the profession, occupation, employment, which are combined with the development of society to put forward new ideas to build SNS ${ }^{[4]}$ network of online career guidance platform for vocational college employment guidance, and to help the establishment of long-term mechanism of employment guidance to really help the students' employment.

\section{Reference}

[1] Yang Weizhong, Zhang Tian. SPSS statistical analysis and industry application case explanation. Tsinghua University press,2011,4

[2] Ryan Gui Hai. Data statistics and analysis: SPSS application course. Peking University Press,2005: 158166.

[3] Liu Dehuan. On order of design, analysis and processing of SPSS. market research,2006,11.

[4] $\mathrm{Wu}$ Jialu. SNS to college students campus passion beckoned. Chinese computer newspaper,2006 